\title{
Relationship between Students' Diagnostic Assessment and Achievement in a Pre-University Mathematics Course
}

\author{
George Tan Geok Shim ${ }^{1}$, Abang Mohammad Hudzaifah Abang Shakawi ${ }^{1} \&$ Farah Liyana Azizan $^{1}$ \\ ${ }^{1}$ Centre for Pre-University Studies, Universiti Malaysia Sarawak (UNIMAS), Kota Samarahan, Sarawak, \\ Malasia \\ Correspondence: George Tan Geok Shim, Pre-University Studies, Universiti Malaysia Sarawak (UNIMAS), \\ 94300, Kota Samarahan, Sarawak, Malasia. E-mail: shimgeorge@unimas.my \\ Received: July 3, 2017 \\ Accepted: July 28, 2017 \\ Online Published: November 7, 2017 \\ doi:10.5539/jel.v6n4p364 \\ URL: http://doi.org/10.5539/jel.v6n4p364
}

\begin{abstract}
Educators have always highlighted the importance of mathematics mastery in education for many years. With the current emphasis of Science, Technology, Engineering and Mathematics (STEMs) education, mathematics mastery is even more vital because it supports the learning and mastery of science fields such as engineering and science. Furthermore, in higher education, mathematics is essential because majority of the courses require the use of mathematical concepts in their learning. In recent years, many countries including Malaysia have seen an increase in the enrolment number of tertiary students. The increase in student enrolment has resulted in a population of students with diverse abilities, and this creates challenges for educators in providing instruction to the students. Educators need to detect students' mathematical ability at an early stage before teaching them new content. One way to gather information about students' basic mathematics skill is through the use of diagnostic test. Diagnostic test in education is a preliminary assessment mainly used to detect students' strengths and weaknesses in learning. It allows educators to cater their teaching style and content to suit to the students' basic knowledge. With researches indicating the importance and benefits of using diagnostic test in various subjects, it is important to further examine the use of diagnostic test in the local context of pre-university studies. This study investigated the relationship between students' mathematics diagnostic test results and final mathematics examination performances at a public pre-university programme. The samples of the study consisted of 250 pre-university students and the data of the study were collected through a mathematics diagnostic test paper, a questionnaire and a final mathematics examination. The outcomes of the study show that there was a strong positive correlation between mathematics diagnostic test results and students' mathematics achievement in pre-university.
\end{abstract}

Keywords: diagnostic testing, mathematics, assessment

\section{Introduction}

\subsection{Introduction}

Educators have always highlighted the importance of mathematics mastery in education. With the current emphasis of Science, Technology, Engineering and Mathematics (STEMs) education, mathematics mastery is even more vital because it can help to support the learning and mastery of science fields such as engineering and science. According to Otung (2001), mathematics is an indispensable tool for engineering because analysis and design of engineering structure and system require mathematical models that capture important parameters and applicable laws. Besides that, mathematics is also important in science to develop formulas in order to discover the value of unknown parameters and geometry that deals with deduction of properties, measurement, and relationship of points, angles, figures and lines in space (Swaranjit, 2015).

In higher education, mathematics is essential because majority of the courses require the use of mathematics concepts in their learning. According to Tang, Voon, and Juhaili (2009), mathematical mastery has become an important indicator to the overall students' academic achievements in university courses. A study by Gillard, Levi and Wilson (2010) also highlighted the importance of mathematics at the university level, where the weaknesses in mathematical skills and lack of confidence in mathematics among first year undergraduate students have become a barrier to the success of many students. Hence, it is vital for university students, 
especially first year students, to have a strong mathematical foundation in order to perform well at the university level.

In recent years, many countries such as Malaysia have seen an increasing number of student enrolment at higher education institutions. This increment in student enrolment however has created a challenging situation for many university educators. According to Batchelor (2004), the increasing access to university education and the diversity of syllabuses and curricula at the school level causes inhomogeneity within each cohort of students. The differences in students' education backgrounds means that educators must devise a way to detect students' mathematical ability at an early stage before teaching them new content from the course. Early detection of students' mathematical weakness will also allow educators to conduct intervention or remedial instruction to assist weak students cope better in the course. One tool that educators can use for this purpose is by using diagnostic testing.

\subsection{What is Diagnostic Testing?}

The term "diagnosis" is commonly used in medical field, where it is defined as a careful, critical study of something to determine its nature (Carpenito-Moyet, 2007). In education, diagnosis can be explained through instructional approach where assessment provides information about students' mastery of relevant prior knowledge and skills within the domain as well as preconception or misconceptions about the material (Ketterlin-Geller \& Yovanoff, 2009). Hence, diagnostic test can be defined as an assessment mainly used to identify students' strengths and weaknesses towards any subjects of learning (Zhao, 2013). It is a direct response to the perceived decline in the mathematical knowledge and skills of new students in relation to the mathematical requirements of their programmes of study (Appleby, Lawson, Croft, Hawkes, Douglas, \& Sleeman, 2000). According to Learning and Teaching Support Network (LTSN) Maths TEAM (2003), diagnostic tests consist of a simple paper based test, computer generated multiple-choice questions or intelligent diagnostic systems and are usually administered during the orientation week or first few weeks of the semester. Alderson (2005, cited in Zhao, 2013) highlighted several characteristics of a diagnostic testing and among them are:

- Diagnostic tests are designed to identify strength and weakness in a learner's knowledge and the use of language;

- Diagnostic tests are more likely to focus on weaknesses than on strengths;

- Diagnostic tests should lead to remediation in further instruction;

- Diagnostic tests give detailed feedback which can be acted upon;

- Diagnostic tests provide immediate results, or results as little delayed as possible after test-taking; and

- Diagnostic test is based on some theory of language development, preferably a detailed theory rather a global theory.

\subsection{Benefits of Implementing Diagnostic Testing in Mathematics}

The results of diagnostic tests have assisted universities in devising instructional approaches to mathematics teaching and curriculum based on students' needs and activities. Subject lecturers also benefited from diagnostic test results, as it could alert them on the students' overall competency in basic mathematical skills for a particular cohort. Furthermore, it can be used as a tool to inform an individual student of any gaps in the level of knowledge he or she is assumed to have and take action to remedy the situation (Sheridan, 2012).

Diagnostic tests have shown to enhance students' performances in areas such as arithmetic and algebra (Atkinson, 2004; cited in Sheridan, 2012). Some studies have also shown that diagnostic testing improves students' performance in other related tests. A study by Betts, Hahn and Zau (2011) concludes that Mathematics Diagnostic Testing Project (MDTP) boosts students' scores on the California Standards Test (CST) Mathematics test. Carmody, Godfrey, and Wood (2006) study on diagnostic testing in a first year mathematics subject also found that there was a positive correlation between mathematics diagnostic tests and students' final examination results. Diagnostic testing also allows fast evaluation of knowledge base and provides immediate mathematics guide for both students and educators (Batchelor, 2004).

\subsection{Purpose of the Study}

Mathematical diagnostic testing among pre-university studies in Malaysian tertiary education could be an important component in assisting students to succeed in their current and future tertiary learning. However, there is a lack of research in this area of the study. Therefore, the paper reports a study that attempted to investigate the 
relationship between students' mathematical diagnostic test results and final examination performances in a pre-university mathematics course at a local public university.

\section{Method}

\subsection{Samples}

The samples of the study consisted of 125 male and 125 female students. They were randomly selected from students who enrolled in a pre-university study programme at a public university in Sarawak, Malaysia.

\subsection{Research Instruments}

The research instrument used in this study consisted of a diagnostic test paper, a questionnaire and a final mathematics examination. The diagnostic test paper was developed by the pre-university program lecturers of the public university with the intention to check the students' prior knowledge and readiness towards the pre-university mathematics courses conducted at the public university. The diagnostic test paper consisted of eight subjective questions which covered basic mathematical concepts such as algebra and calculus (differentiation and integration). On the other hand, the questionnaire consisted of five items related to the students' demographic information such as gender and their Malaysian Certificate of Education (MCE) mathematics and additional mathematics results.

\subsection{Research Procedure}

The study was conducted in three stages within the duration of two consecutive semesters of pre-university studies. At the beginning of the first semester, the students were given the mathematics diagnostic test paper and a questionnaire. Students were asked to complete the mathematics diagnostic test within one hour and the questionnaire after the test. The pre-university mathematics courses were conducted without considering the outcome of the diagnostic test to ensure equal treatment towards the teaching of the students in the classes.

At the end of the second semester, the students' mathematics final examination results for both Semester 1 and Semester 2 were collected and data obtained from the mathematics diagnostic test, questionnaire and mathematics final examination results were analysed using Statistical Package for the Social Science (SPSS) version 23.0 software. Descriptive statistics were used to analyse the demographic information of the students while inferential statistics in the form of Pearson Moment correlation was used to investigate the relationship between students' mathematics diagnostic test and the students' mathematics achievement in pre-university.

\section{Results}

\subsection{Students' Achievement in Malaysian Certificate of Education (MCE) Mathematics}

Table 1 shows the pre-university students' achievement in Malaysian Certificate of Education (MCE) Mathematics. Based on the table, it showed that the majority of the pre-university students obtained an A- in their MCE Mathematics (49.2\%). This was followed by A+ (46.9\%), A (3.1\%) and B (0.8\%).

Table 1. Pre-university students' achievement in Malaysian Certificate of Education (MCE) Mathematics

\begin{tabular}{cccccc}
\hline \multicolumn{5}{c}{ SPM MATHEMATICS } \\
\hline \multirow{6}{*}{ Valid } & Frequency & Percentage & Valid Percent & Cumulative Percentage \\
& A & 122 & 46.9 & 46.9 & 46.9 \\
& A- & 128 & 49.2 & 49.2 & 96.2 \\
& $\mathrm{~A}$ & 8 & 3.1 & 3.1 & 99.2 \\
& $\mathrm{~B}+$ & 2 & 0.8 & 0.8 & 100.0 \\
& Total & 260 & 100.0 & 100.0 & \\
\hline
\end{tabular}

\subsection{Students' Achievement in Malaysian Certificate of Education (MCE) Additional Mathematics}

Table 2 shows the pre-university students' achievement in Malaysian Certificate of Education (MCE) Additional Mathematics. Based on the table, it showed that majority of the pre-university students obtained a $\mathrm{B}+$ in their MCE Additional Mathematics (26.2\%). This was followed by A- $(21.5 \%)$, B (18.8\%), A (16.5\%), C+ (10.4\%), $\mathrm{A}+(6.2 \%)$ and $\mathrm{C}(0.4 \%)$. 
Table 2. Pre-university students' achievement in Malaysian Certificate of Education (MCE) Additional Mathematics

\begin{tabular}{|c|c|c|c|c|c|}
\hline \multicolumn{6}{|c|}{ SPM ADDITIONAL MATHEMATICS } \\
\hline & & Frequency & Percentage & Valid Percent & Cumulative Percentage \\
\hline \multirow[t]{8}{*}{ Valid } & $\mathrm{A}+$ & 16 & 6.2 & 6.2 & 6.2 \\
\hline & A- & 56 & 21.5 & 21.5 & 27.7 \\
\hline & $\mathrm{A}$ & 43 & 16.5 & 16.5 & 44.2 \\
\hline & $\mathrm{B}+$ & 68 & 26.2 & 26.2 & 70.4 \\
\hline & $\mathrm{B}$ & 49 & 18.8 & 18.8 & 89.2 \\
\hline & $\mathrm{C}+$ & 27 & 10.4 & 10.4 & 99.6 \\
\hline & $\mathrm{C}$ & 1 & 0.4 & 0.4 & 100.0 \\
\hline & Total & 260 & 100.0 & 100.0 & \\
\hline
\end{tabular}

\subsection{Mean, Standard Deviation and Pearson Correlation between the Mathematics Diagnostic Test Results and the Students' Mathematical Achievement in Pre-University}

Tables 3 and 4 show the mean, standard deviation and Pearson correlation between the mathematics diagnostic test results and the students' mathematical achievement in pre-university. Based on the table, it showed that there was a positive correlation between mathematics diagnostic test (Mean $=78.90, \mathrm{SD}=11.569)$ and the students' mathematical achievement in pre-university (Mean $=73.09, \mathrm{SD}=11.104)$, with $\mathrm{r}=0.628, \mathrm{p} \leq 0.000, \mathrm{~N}=250$.

Table 3. Mean and standard deviation of mathematics diagnostic test and students' mathematical achievement

\begin{tabular}{lccc}
\hline \multicolumn{4}{c}{ Descriptive Statistics } \\
\\
\hline Mean & Std. Deviation & $\mathrm{N}$ \\
\hline Mathematics Diagnostic Test & 78.90 & 11.569 & 125 \\
Pre-U Mathematics Achievement & 73.09 & 11.104 & 125 \\
\hline
\end{tabular}

Table 4. Pearson correlation results between diagnostic test results and students' mathematical achievement

\begin{tabular}{llll}
\hline Correlations & & & \\
\hline & & Mathematics Diagnostic Test & Pre U Mathematics Achievement \\
\hline \multirow{2}{*}{ Mathematics Diagnostic Test } & Sig. (2-tailed) & 1 & $0.628^{* *}$ \\
& $\mathrm{~N}$ & 250 & 0.000 \\
& Pearson Correlation & $0.628^{* *}$ & 250 \\
Pre-U Mathematics Achievement & Sig. (2-tailed) & 0.000 & 1 \\
& $\mathrm{~N}$ & 250 & 250 \\
\hline
\end{tabular}

**. Correlation is significant at the 0.01 level (2-tailed).

Figure 1 shows the scatterplot that summarised the correlation between mathematics diagnostic test results and students' mathematical achievement. Overall, there was a strong positive correlation between mathematics diagnostic test results and students' mathematics achievement in pre-university. 


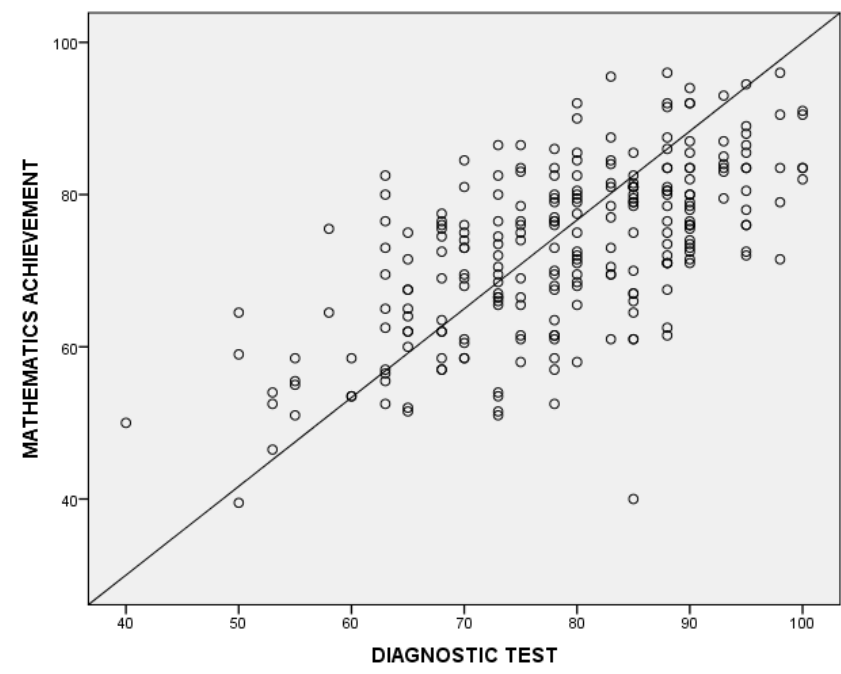

Figure 1. Scatterplot between mathematics diagnostic test results and students' mathematical performances

\subsection{Mean, Standard Deviation, and Pearson Correlation between the Mathematics Diagnostic Test Results and the Students' Mathematical Achievement in Pre-University Based on Gender}

Tables 5 and 6 show the mean, standard deviation and Pearson correlation between the mathematics diagnostic test results and the students' mathematical achievement in pre-university based on gender. Based on the table, it showed that for male students, there was a positive correlation between mathematics diagnostic test (Mean = $78.38, \mathrm{SD}=11.914$ ) and the students' mathematical achievement in pre-university (Mean $=70.98, \mathrm{SD}=10.962$ ), with $\mathrm{r}=0.612, \mathrm{p} \leq 0.000, \mathrm{~N}=125$. For female students, there was also positive correlation between mathematics diagnostic test $($ Mean $=79.43, \mathrm{SD}=11.237)$ and the students' mathematical achievement in pre-university (Mean $=75.21, \mathrm{SD}=10.882$ ), with $\mathrm{r}=0.653, \mathrm{p} \leq 0.000, \mathrm{~N}=125$.

Table 5. Mean and standard deviation of diagnostic test results and students' mathematical achievement based on gender

\begin{tabular}{lllll}
\hline Descriptive Statistics & & & \\
\hline & & Mean & Std. Deviation & $\mathrm{N}$ \\
\multirow{2}{*}{ Male } & Mathematics Diagnostic Test & 78.38 & 11.914 & 125 \\
& Pre-U Mathematics Achievement & 70.98 & 10.962 & 125 \\
\multirow{2}{*}{ Female } & Mathematics Diagnostic Test & 79.43 & 11.237 & 125 \\
& Pre-U Mathematics Achievement & 75.21 & 10.882 & 125 \\
\hline
\end{tabular}

Table 6. Pearson correlation results between diagnostic test results and students' mathematical achievement based on gender

\begin{tabular}{lllll}
\hline Correlations & & & \\
\hline & & & Mathematics Diagnostic \\
Test & $\begin{array}{l}\text { Pre-U Mathematics } \\
\text { Achievement }\end{array}$ \\
\hline \multirow{2}{*}{ Male } & & Pearson Correlation & 1 & $.612^{* *}$ \\
& Mathematics Diagnostic Test & Sig. (2-tailed) & & .000 \\
& & $\mathrm{~N}$ & 125 & 125 \\
& Pre-U Mathematics & Pearson Correlation & $.612^{* *}$ & 1 \\
\hline
\end{tabular}




\begin{tabular}{lllll}
\hline & $\mathrm{N}$ & 125 & 125 \\
& & Pearson Correlation & 1 & $0.653^{* *}$ \\
Female & Mathematics Diagnostic Test & Sig. (2-tailed) & & 0.000 \\
& & $\mathrm{~N}$ & 125 & 125 \\
& & Pearson Correlation & $0.653^{* *}$ & 1 \\
& Pre-U Mathematics & Sig. (2-tailed) & 0.000 & 125 \\
\hline
\end{tabular}

**. Correlation is significant at the 0.01 level (2-tailed).

Figures 2 and 3 show the scatterplots that summarised the correlations between mathematics diagnostic test results and students' mathematical achievement for male and female students. Overall, both male and female students show strong positive correlations between mathematics diagnostic test results and students' mathematics achievement in pre-university.

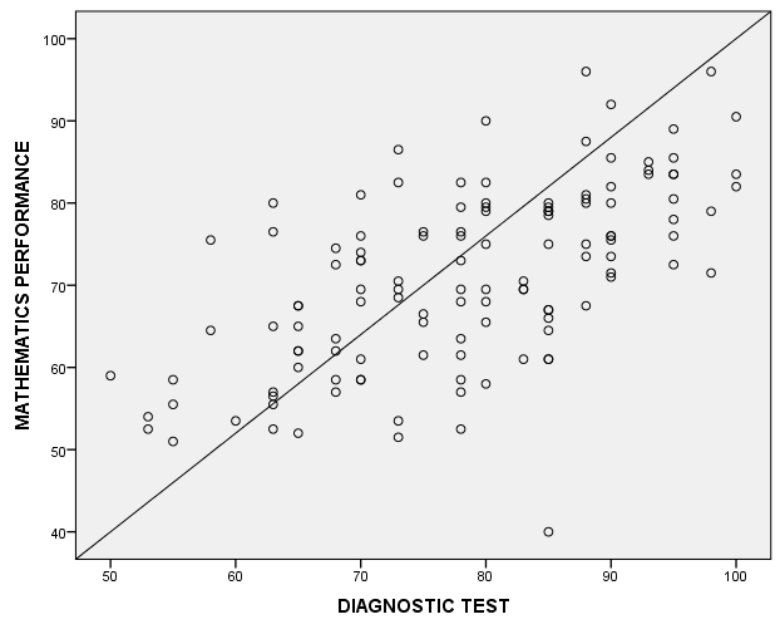

Figure 2. Scatterplot between mathematics diagnostic test results and students' mathematical performances for male students

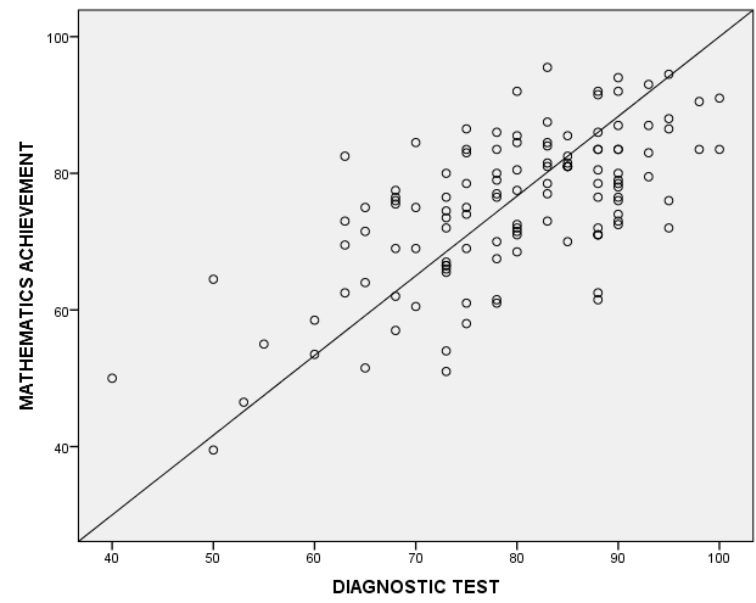

Figure 3. Scatterplot between mathematics diagnostic test results and students' mathematical performances for female students 


\section{Discussion}

The results of the study indicated that students who performed well in their diagnostic test also performed well in their mathematics final assessments. Likewise, those who did not perform well in their diagnostic test obtained poor results in their final mathematics assessment. The result of this study supported Carmody et al. (2006)'s study which also found that there was a significant positive correlation between the students' diagnostic test and the final examination. Sheridan (2012)'s study on mathematics diagnostics testing for first year tertiary students also highlighted that there was a positive correlation between mathematics diagnostic testing and the semester 1 mathematics test result.

Overall, students' prior knowledge in mathematics affected their performance in the study. Students with poor basic knowledge in mathematics, as detected by the mathematics diagnostic test, had difficulties in coping with the new syllabus offered in the pre-university level. This is because majority of the mathematics syllabus in pre-university level requires the basic knowledge in secondary schools' mathematics (modern mathematics and additional mathematics) as its prerequisite requirement for the subject. Hence, it is very important for educators to detect students' basic knowledge before teaching them the new content as it allows educators to understand the current state of their students' knowledge and to plan intervention strategies in their teaching to deal with the issue.

Diagnostic testing is a valuable tool for educators to detect students' strength and weakness in learning subjects such as mathematics. With the outcome of this study, it is hoped that educators can see the potential of diagnostic testing in teaching and learning and apply it in the beginning of every course in university. Future studies possibly arising from the study include a plan to determine the different kinds of weakness students have prior to the pre-university mathematics course as well as to implement effective intervention strategies to ensure academic success.

\section{Acknowledgments}

Firstly, we would like to take this opportunity to thank Universiti Malaysia Sarawak (UNIMAS) for providing sufficient funds for this study. Special thanks to Professor Dr. Hong Kian Sam, Madam Rebecca Lee Su Ping and Madam Gan Siew Ling for their invaluable assistances, advices and ideas throughout this study. Finally, we would like to express our appreciation to our families and friends for all their support.

\section{References}

Appleby, J., Lawson, D., Croft, T., Hawkes, T., Douglas, Q., \& Sleeman, B. (2000). Diagnostic testing in theory and practice. Measuring the mathematics problem. Retrieved October 10, 2016, from http://www.engc.org.uk/engcdocuments/internet/Website/Measuring\%20the\%20Mathematic\%20Problems. pdf

Batchelor, H. (2004). The importance of a mathematics diagnostic test for incoming pharmacy undergraduates. Pharmacy Education, 4(2), 69-74. https://doi.org/10.1080/15602210410001715626

Betts, J. R., Hahn, Y., \& Zau, A. C. (2011). Does diagnostic math testing improve student learning. Retrieved October 20, 2016, from http://www.ppic.org/content/pubs/report/R_1011JBR.pdf

Carmody, G., Godfrey, S., \& Wood, L. (2012, October). Diagnostic tests in a first year mathematics subject. In Proceedings of the Australian Conference on Science and Mathematics Education (formerly UniServe Science Conference). Retrieved November 12, 2016, from http://sydney.edu.au/science/uniserve_science/pubs/procs/2006/carmody.pdf

Carpenito-Moyet, L. J. (2007). Nursing diagnosis: Application to clinical practice (14th ed.). Philadelphia, PA: Lippincott.

Gillard, J., Levi, M., \& Wilson, R. (2010). Diagnostic testing at UK universities: An email survey. Teaching Mathematics and its Application, 29, 51-63. https://doi.org/10.1093/teamat/hrq004

Ketterlin-Gelle, L. R., \& Yovanoff, P. (2009). Diagnostic assessments in mathematics to support instructional decision making. Practical Assessment, Research \& Evaluation, 14(16), 1-11.

Learning and Teaching Support Network (LTSN) Maths TEAM. (2003). Diagnostic Testing for Mathematics. LTSN MathsTEAM Project. Retrieved October 10, 2016, from http://www.ltsn.ac.uk/mathstream

Otung, I. E. (2001). Reassessing the mathematics content of engineering education. Engineering Science and Education Journal, 10(4), 130-138. https://doi.org/10.1049/esej:20010401 
Sheridan, B. (2012). How much do our incoming first year students know? Diagnostic testing in mathematics at third level. Teaching Fellowship, 24, 40-45.

Swaranjit, K. (2015). Application of mathematics in sciences. International Journal of IT, Engineering and Applied Sciences Research, 4(6), 83-85.

Tang, H. E., Voon, L. L., \& Julaihi, N. H. (2009). A case study of "High-Failure Rate" mathematics courses and its' contributing factors on UiTM Sarawak diploma students. Paper presented at the Conference on Scientific \& Social Research (14-15 March 2009).

Zhao, Z. (2013). An overview of studies on diagnostic testing and its implication for the development of diagnostic speaking test. International Journal of English Linguistics, 3(1), 41-45. https://doi.org/10.5539/ijel.v3n1p41

\section{Copyrights}

Copyright for this article is retained by the author(s), with first publication rights granted to the journal.

This is an open-access article distributed under the terms and conditions of the Creative Commons Attribution license (http://creativecommons.org/licenses/by/4.0/). 